\title{
Comfort Evaluation of Non Occlusal Intraoral Appliance Use During Sleep in Patients with Muscular Temporomandibular Dysfunction
}

\author{
Evaluación del Confort del Uso Durante el Sueño de Un Aparato Intraoral \\ No Oclusal en Pacientes con Disfunción Temporomandibular Muscular
}

Imahar Cavassaki"; Iván Suazo Galdames ${ }^{* *}$ \& Antônio Sérgio Guimarães*

CAVASSAKI, I.; SUAZO GALDAMES, I. \& GUIMARÃES, A. S. Comfort evaluation of non-occlusal intraoral appliance use during sleep in patients with muscular temporomandibular dysfunction. Int. J. Odontostomat., 7(3):351-357, 2013.

ABSTRACT: The aim of this study was the evaluation of the discomfort level during the utilization of non oclusal intraoral appliance during sleep in patients with muscular temporomandibular dysfunction; time of acceptance; and the effectiveness of non oclusal intraoral appliance related to the relief of pain symptoms. We evaluated 30 patients from Orofacial Pain and Temporomandibular Dysfunction Clinic (UNIFESP/EPM/HSP) with muscular temporamandibular dysfunction, 25 females and 5 males, between 19 to 60 years. We used a non-oclusal intraoral appliance, based on the model developed by Minagi et al. (2001). Patients was conducted to use the appliance during all sleeping period e to persist in use, even when there was any kind of discomfort, which would be natural during the adaptation period, for 30 consecutive days. After this period, the researcher interviewed all patients, answering specific questions designed for this study. The mean time for adaptation was 4 days. Of all patients, $23.33 \%$ had no difficulty in adapting the appliance, with immediate acceptance. The gradual reduction in the intensity of myofascial pain and discomfort, as well as improving the quality of life in $78.3 \%$ of the sample confirmed the effectiveness of non-oclusal palatal intraoral appliance without occlusal contact in relieving the painful symptoms of muscular TMD.

KEY WORDS: intraoral appliance, temporomandibular joint, temporomandibular joint disorders.

\section{INTRODUCTION}

It is recommended for treatment of temporomandibular disorders (TMD) to be as conservative and less invasive as possible to reduce pain, to improve chewing function and quality of life (Palla, 2004; Carlsson et al., 2006; Okeson, 2008; Klasser \& Greene, 2009; Leeuw, 2010; Sessle et al., 2010). An interocclusal appliance represents an effective treatment option for patients with TMD. Until now, interocclusal appliance mechanism of action is not completely understood, but a variety of mechanisms or their combination is most likely responsible for this. Many different interocclusal appliances were presented in the literature, each with its own specific indications. The most common device is the stabilizer.

Balanced splints are generally made for the maxillary arch and provide an ideal occlusal relationship considered for the patient. Studies have shown that using this splint can reduce the parafunctional activity that often accompanies periods of stress. Balanced splints, also known as Michigan's splint, aim to restore and stabilize the craniomandibular relations, extended to the cervical spine stability (Carlsson et al.; Okeson; Maciel \& Gil, 2010; Leeuw).

Greene \& Laskin (1972) related that the reasons for success with non-occlusive appliance are due not only to the psychological effects, but also the change of habitual neuromuscular patterns of chewing muscles and invasion of space available for the tongue taking a reflex fall the mandibular rest position. Tsuga et al., (1986) and Cassisi et al. (1987) developed studies on the effect of non-occlusal intraoral appliance in the treatment of TMD, but not referred to the importance of the thickness and weight of the palatal plate.

\footnotetext{
* Instituto da Cabeça, Universidade Federal de São Paulo, Escola Paulista de Medicina, Brasil

* Universidad Autónoma de Chile, Chile.
} 
Greene \& Laskin developed a comparative study with three types of appliances to relieve the symptoms of TMD patients. Eighty-seven percent of the 71 treated patients showed improvement, and in $40 \%$ was observed pain relief. Minagi et al. (2001) evaluated the effects of the thickness of the palatal appliance on muscular symptoms in craniomandibular disorders. This study showed clinical data from a preliminary study using an intraoral appliance with a thicker base resin on the symptoms of TMD in 18 patients. It was concluded that the thick palatal appliance was an important factor in achieving improvement in signs and symptoms of muscular TMD. Hasegawa et al. (2007) developed a non-occlusal intraoral palatal appliance and studied their effect on masseter muscle during sleep. Noting EMG patterns have noted that the thick palatal appliance has an active effect on suppression of masseter muscle activity.

The aim of this study was intended to ascertain: the level of discomfort in the use of non occlusal intraoral appliance during sleep in patients with muscular TMD, and the time of acceptance, effectiveness of palatal intraoral appliance without occlusal contact in the relief of painful symptoms of muscular TMD.

\section{MATERIAL AND METHOD}

We evaluated 30 patients treated at the Clinic of Orofacial Pain and Temporomandibular Disorders at UNIFESP / EPM / HSP, with muscular TMD, 25 females and 5 males, aged 19 to 60 years. We made the impressions of dental arches, upper and lower alginate and, after obtaining models castings in orthodontic dental stone, made the dental appliance itself.

The preparation was done in three steps. The first coating was made palatal covering with acrylic resin pressed. Then, the manufacture of resin blade sandwiched between two glass plates, bound and immersed in water in a pot with regulator alleges that 30 pounds of air pressure to eliminate air bubbles in the resin. This blade of resin was cut up and adapted to all the upper teeth in the equatorial region, except the four upper incisors. Halfway through the first upper molar a slope of resin was started to the height of the distal half of the second molar. In the third stage began in the total closure of the upper palate, to which, in the second half of the molar fraction of the other blade pressed to cover the distal row of the second molar, called the Ah line. Confected are two staples in the distal of second molar in semicircular shape. It was given the final polish. Hydrostatic test was performed keeping the device submerged in water at a depth of two meters during $24 \mathrm{~h}$ (Figs. 1, 2 and 3).

With the dental appliance in full condition of use, the patient was guided to use it for all sleeping periods and persist in use, even though there was some initial discomfort, which is the natural adaptation, for 30 continuous days.

After this period, patients were interviewed by the researcher and responding to specific questions formulated for the study:

1. Tongue injury - it was uncomfortable or not;

2. Nausea - felt or not and how long it took while using the device;

3. Salivation - if the device caused or intensified;

4. Breathing - if there was any difficulty in breathing or noticed any change;

5. Sleep disorder - if there was any change;

6. Adaptation to device - how much time needed to adapt to the device;

7. Wake up with pain - if there was a sense of relief of painful symptoms upon awakening;

8. Subjective evaluation of pain - using the visual analogue scale (VAS) patients were asked to classify their pain after the treatment.

Statistical analysis. Chi-square test (X2) was used to assess the association between qualitative variables and Mann-Whitney, Kruskal Wallis test to compare the outcome variables. The data were presented through descriptive measures. Data analysis was performed using MedCalc and results were declared significant when $\mathrm{P}<0.05$.

\section{RESULTS}

Of the 30 patients included, 25 were female and five male, aged 19 to 60 years. Most study participants were female $(83 \%)$, mean age of 37 years and standard deviation of 12. The application of the MannWhitney test showed no significant difference $(p=$ 0.4525 ) for average age of men compared with the average age of women.

Table I shows that among the complaints lodged by patients after the onset of the palatal appliance: 


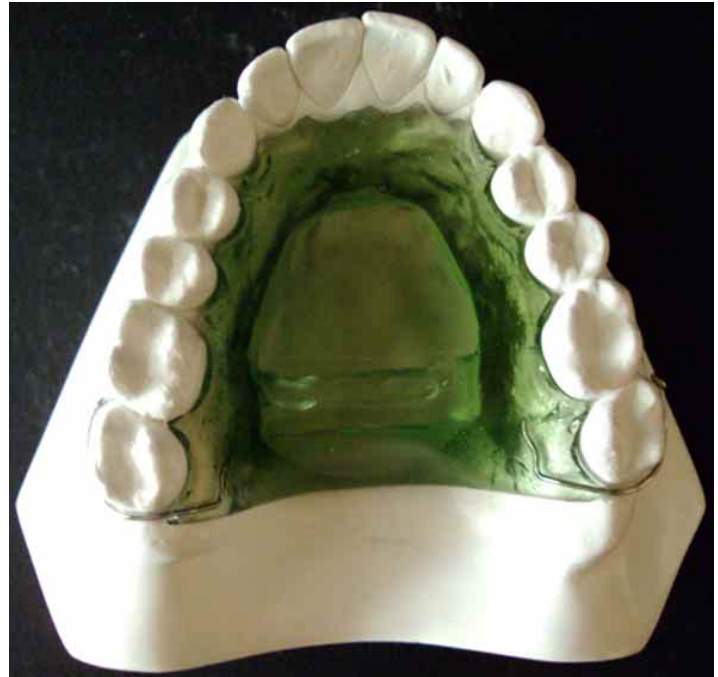

Fig. 1. Intraoral appliance, occlusal view.

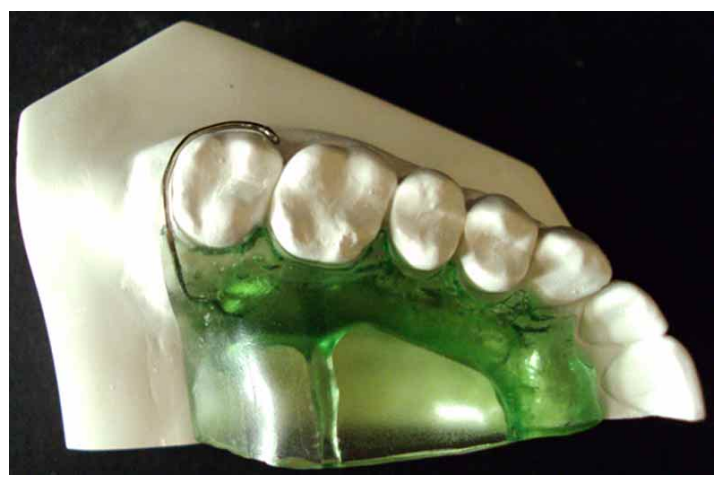

Fig. 2. Intraoral appliance, occlusal view sectioned to visualize the concavity.

$100 \%$ reported no tongue injury, $77 \%$ reported no nauseas, $66 \%$ did not complain of drooling, $73.33 \%$ had no difficulty in breathing, $83.33 \%$ had no change in sleep, and $23.33 \%$ had no difficulty in adapting to the device. Of the seven patients who experienced nausea, $57 \%$ had relief within 3 days, $29 \% 7$ to 10 days and only one patient required 15 days to get rid of the discomfort. Of the 10 patients who complained of drooling, $50 \%$ was only for a day, with low intensity for two patients. Of the eight who had some difficulty in breathing, $20 \%$ felt discomfort after initial standard three or five days and $6 \%$ after six or seven days. Of the five who had sleep disorders, they improved after two, three, five or seven days. The average time to adapt to the unit for 23 patients who had immediate acceptance was four days, with a maximum of fifteen days.

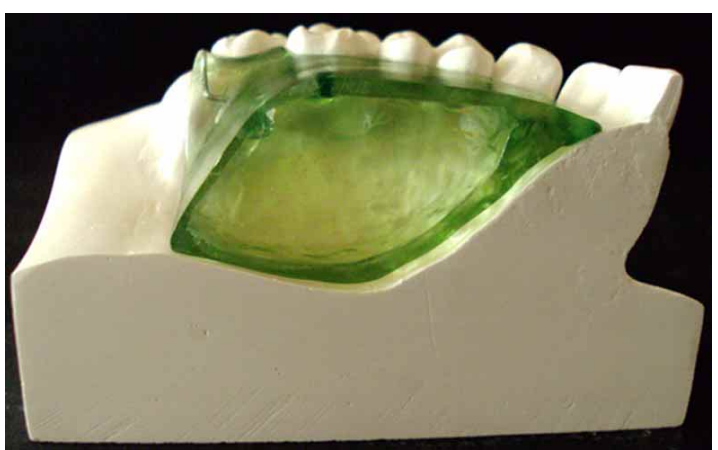

Fig. 3. Intraoral appliance, cross-sectional view of the concavity for viewing.

Table I. Distribution of patients according to the complaints investigated after 30 days of use of the device.

\begin{tabular}{|c|c|c|c|c|c|}
\hline \multirow{2}{*}{ Claim } & \multicolumn{2}{|c|}{ Absent } & \multicolumn{2}{|c|}{ Present } & \multirow{2}{*}{ Duration } \\
\hline & $\mathbf{n}$ & $\%$ & $\mathbf{n}$ & $\%$ & \\
\hline Tongue Injury & 30 & 100 & 0 & 0 & 0 \\
\hline \multirow[t]{3}{*}{ Nausea } & 23 & 77 & 4 & 13 & 1 to 3 \\
\hline & & & 2 & 7 & 7 to 10 \\
\hline & & & 1 & 3 & 15 \\
\hline \multirow[t]{3}{*}{ Drooling } & 20 & 66 & 5 & 16.66 & 1 \\
\hline & & & 3 & 10 & 3 to 5 \\
\hline & & & 2 & 7 & 7 \\
\hline \multirow[t]{4}{*}{ Difficulty breathing } & 22 & 73.33 & 3 & 10 & 3 \\
\hline & & & 3 & 10 & 5 \\
\hline & & & 1 & 3.33 & 6 \\
\hline & & & 1 & 3,33 & 7 \\
\hline \multirow[t]{4}{*}{ Sleep disorders } & 25 & 83.33 & 1 & 3.33 & 2 \\
\hline & & & 2 & 6.67 & 3 \\
\hline & & & 1 & 3.33 & 5 \\
\hline & & & 1 & 3.33 & 7 \\
\hline \multirow[t]{3}{*}{ Adaptation } & 7 & 23.33 & 9 & 30 & 1 to 3 \\
\hline & & & 10 & 33.33 & 4 to 7 \\
\hline & & & 4 & 13.33 & 10 to 15 \\
\hline
\end{tabular}

It was proved by Kruskall Wallis test that there's no difference between the ages of patients related to complaints investigated 30 days after using the device, injury to the tongue, nausea, drooling, difficulty breathing, sleep disorders and adaptation to appliance.

According to Table II, $73 \%$ of patients reported feeling relief from painful symptoms on waking, and $27 \%$ related feel excellent or good at awakening, after 30 days using dental appliance.

Using the qui-square test, it appears that the perception of improvement is independent of the chewing muscle involved in TMD $(p=0.81)$. Considering the scale of 0 to $100 \%$ for the subjective perception of improvement was observed that for 
$10 \%$ of patients the intensity of improvement was $<70 \%$ to $63 \%$ of them were $70 \%$ to $85 \%$ and $27 \%$ for the other was> $85 \%$, as shown in Table III.

The overall improvement in the sample for the relief of painful symptoms in the muscles of mastication involved in TMD was $78.3 \%$.

Table II. Improvement in painful symptoms experienced by patients after 30 days of use of dental appliance.

\begin{tabular}{lcc}
\hline Awakening sensation & $\mathbf{n}$ & $\mathbf{\%}$ \\
\hline Relief & 22 & $73.33 \%$ \\
Good & 4 & $13.33 \%$ \\
Excellent & 4 & $13.33 \%$ \\
Total & 30 & $100.00 \%$ \\
\hline
\end{tabular}

In the study of association between factors we observed that the absence of drooling explains the perception of improved sleep quality $(p=0.009)$ and also explains the improvement of breathing $(p=-0.029)$. We also observed a significant association between the variables breathing and perception of improvement $(p=0.033)$ and between variables breath and sleep improvement $(p=0.001)$, as shown in Table IV.

According to Figure 4 shows that there is a statistically significant moderate correlation between age and time of acceptance. In Figure 5 we can see that there is no significant negative weak correlation between age and scale of perception and in Figure 6 we can observe that there is no significant negative weak correlation between time of acceptance and perception scale.

Table III. Perception of improvement based on the Visual Analogue Scale (VAS) in the chewing muscle involved in TMD.

\begin{tabular}{lccc}
\hline $\begin{array}{l}\text { Perception of improvement } \\
\mathbf{0} \text { to } \mathbf{1 0 0} \%\end{array}$ & \multicolumn{4}{c}{ Chewing muscle involved in TMD } \\
Masseter muscle & Masseter and Temporalis & \\
\hline $50 \%$ & 1 & 0 & $1(3.3 \%)$ \\
$60 \%$ & 1 & 1 & $2(6.7 \%)$ \\
$70 \%$ & 4 & 4 & $8(26.7 \%)$ \\
$80 \%$ & 4 & 5 & $9(30.0 \%)$ \\
$85 \%$ & 0 & 2 & $2(6.7 \%)$ \\
$90 \%$ & 3 & 3 & $6(20.0 \%)$ \\
$95 \%$ & 1 & 1 & $2(6.7 \%)$ \\
& $14(46.7 \%)$ & $16(53.3 \%)$ & 30 \\
\hline
\end{tabular}

Chi-square test descriptive value: $\mathrm{P}=0.81$

Table IV. Results of the study of association between factors.

\begin{tabular}{lccc}
\hline Factor & Factor & Chi-square value & $\boldsymbol{P}=$ \\
\hline \multirow{2}{*}{ Drooling } & Sleep & 66.973 & 0.009 \\
& Breathing & 60.902 & 0.029 \\
\hline \multirow{2}{*}{ Perception of improvement } & Breathing & 38.131 & 0.033 \\
& Sleep & 50.813 & 0.001 \\
\hline
\end{tabular}

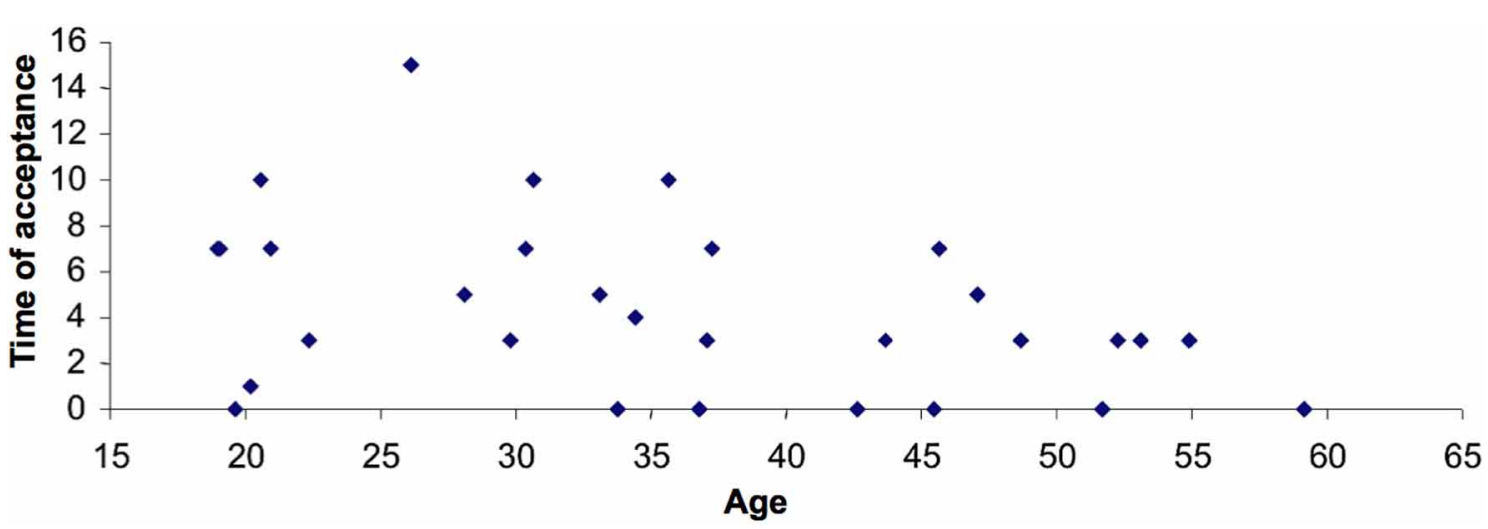

Fig. 4. Age vs. Time of acceptance. Moderate negative correlation $(r=-0.40)$ and $p=0.03^{*}$. 


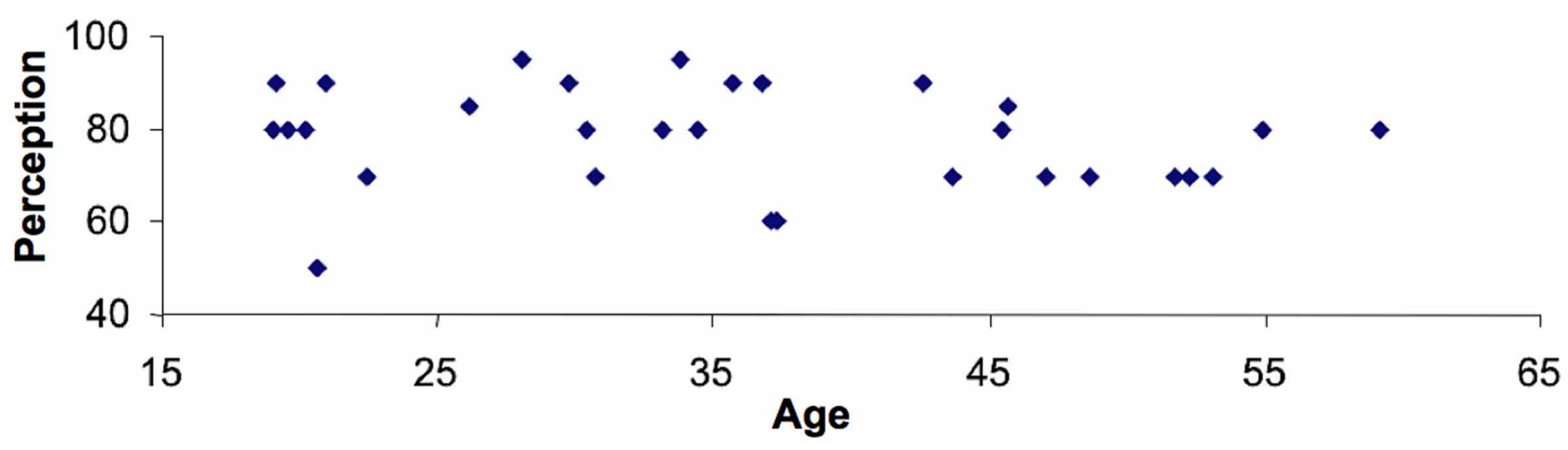

Fig. 5. Age vs. Perception. Weak negative correlation ( $r=-0.17)$ and $p=0.3639$ (non-significant).

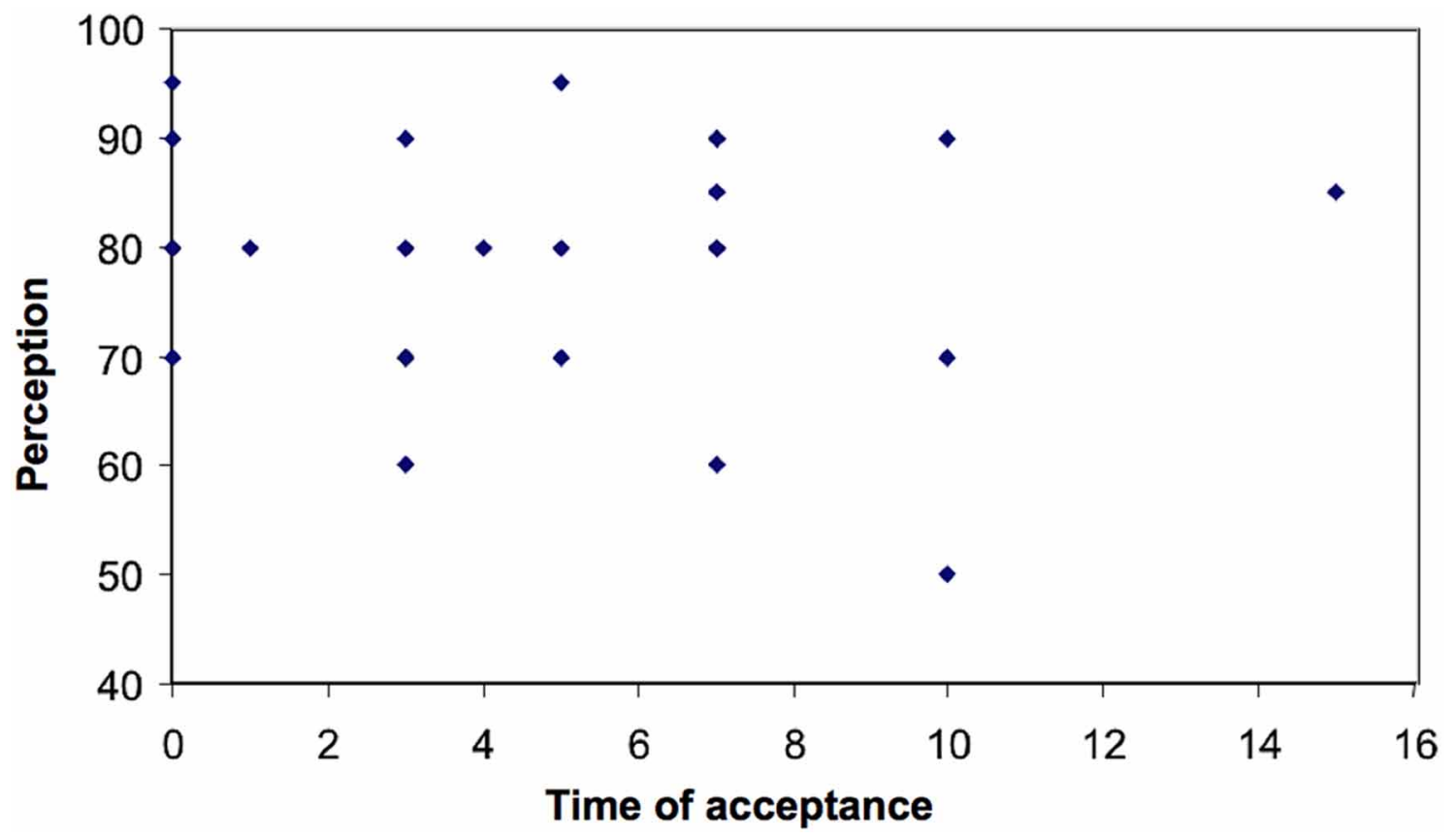

Fig. 6. Perception vs. Time of acceptance. Weak negative correlation ( $r=-0.11) p=0.5795$ (non-significant).

\section{DISCUSSION}

The non-occlusal intraoral appliance has some advantages over splints, it does not require frequent adjustment, it is easier to use and does not compromise the occlusion. A non-occlusal intraoral appliance model developed by Minagi et al. was used in this work, which evaluated the effects of the thickness of an intraoral palatal appliance to relieve symptoms of muscular TMD, and intended to show how the thickness of an intraoral appliance designed to fill the concavity of the palate may interfere with treatment outcome. Other studies suggest that treatment with the thick intraoral appliance is possibly a more effective method for an initial improvement in muscle symptoms and can result in an improved quality of life of patients with TMD. The thickness of the palatal plate seems to be an important factor to obtain the desired clinical effect. 
When used in patients with normal palate the result of the device was satisfactory, however, by the device is completely filled with resin, and in patients with deep palate there would certainly be uncomfortable due to weight. Modifying the technique to make this intraoral appliance, we were able to considerably reduce the weight (up to $38 \%$ ) and hence the discomfort of these patients.

Assessing the level of discomfort in the use of non occlusal intraoral appliance during sleep for 30 consecutive days in patients with muscular TMD, we found that $100 \%$ reported no injury to the tongue, $77 \%$ reported no nausea, $66 \%$ did not complain of drooling, $73.33 \%$ had no difficulty breathing and, $83.33 \%$ had no change in sleep.

The average time to adapt to the unit was 4 days, up to 15 days. Of all the patients, $23.33 \%$ had no difficulty in adapting to the appliance, with immediate acceptance.

The gradual reduction in the intensity of myofascial pain and discomfort, as well as improving the quality of life in $78.3 \%$ of the sample confirmed the effectiveness of non-occlusal intraoral appliance in relieving the painful symptoms of muscular TMD. The relief of symptoms with the use of the device found by thick palatal Minagi et al. was $77.6 \%$. Greene \& Laskin used in their research, non-occlusal intraoral appliance as a placebo and found a $40 \%$ improvement. According to the authors, the reasons for success with nonocclusal appliance are due not only to the psychological effects, but also the change of habitual neuromuscular patterns within the chewing muscles, and invasion of space available for the tongue taking a reflex fall of position mandibular rest. Observing EMG patterns, Hasegawa et al. related that the thick palatal appliance has an active effect on suppression of masseter muscle activity.

In our study, considering the scale of 0 to $100 \%$ for the subjective perception of improvement, was observed that in $10 \%$ of patients the intensity of improvement was $<70 \%$, to $63 \%$ of them, it was $70 \%$ to $85 \%$ and for the remaining $27 \%$, it was $>85 \%$. Applying the qui-square test, it was found that the perception of improvement was independent of the chewing muscle affected, because there was no significant difference $(p=0.855)$ among patients with TMD in the region of the masseter and those who presented TMD in the region of the masseter and temporalis muscles.

Based on the assumption previously related by Minagi et al. supported by our research, that the thick palatal appliance seems to have more satisfactory results in patients with dental arch wider than those with narrower dental arch, later studies can be made. Would be interesting to see if palates in deep, shallow or no difference in average mean relief of symptoms of muscular TMD using the thick palatal appliance.

\section{ACKNOWLEDGMENTS}

The authors express their sincere thanks to Silvia Cristina Borragini Abuchaim, biomedical, for the scientific review of this article; Dr. Maria Imaculada de Lima Montebelo, PhD in Biostatistics Applied to Agronomy and Biostatistics Professor at Methodist University of Piracicaba, by statistical analysis.

CAVASSAKI, I. SUAZO GALDAMES, I. \& GUIMARÃES, A. S. Evaluación del confort del uso durante el sueño de un aparato intraoral no oclusal en pacientes con disfunción temporomandibular muscular. Int. J. Odontostomat., 7(3):351357, 2013.

RESUMEN: El objetivo fue evaluar la respuesta al uso de un aparato intraoral no oclusal durante el sueño en pacientes con disfunción temporomandibular (DTM) muscular. Se evaluaron 30 pacientes de la Clínica de Dolor Orofacial y Disfunción Temporomandibular (UNIFESP/EPM/HSP) con diagnóstico de DTM muscular, 25 mujeres y 5 hombres, entre 19 y 60 años. Se utilizó un aparato intraoral no oclusal, basado en el modelo desarrollado por Minagi et al. (2001) y se evaluó el tiempo de adaptación al aparato y la eficacia en términos de reducción del dolor. Los pacientes utilizaron el aparato al acostarse y mientras dormían por 30 días contínuos. Después de este período, todos los pacientes fueron entrevistados. El tiempo medio para la adaptación fue de 4 días. De todos los pacientes, el 23,33\% no tuvo ninguna dificultad de adaptación al aparato, con aceptación inmediata. La reducción gradual en la intensidad del dolor miofascial y el malestar, así como la mejora de la calidad de vida en el $78,3 \%$ de la muestra confirmó la eficacia del aparato intraoral para aliviar los síntomas dolorosos de DTM muscular.

PALABRAS CLAVE: aparato intraoral, articulación temporomandibular, disfunción temporomandibular. 


\section{REFERENCES}

Carlsson, G. E.; Magnusson, T. \& Guimarães, A.S. Tratamento das Disfunções Temporomandibulares na Clínica Odontológica. São Paulo, Quintessence, 2006.

Cassisi, J. E.; McGlynn, F. D. \& Mahan, P. E. Occlusal splint effects on nocturnal bruxing. An emerging paradigm and some early results. Cranio, 5(1):64-8, 1987.

Greene, C. S. \& Laskin, D. M. Splint therapy for the myofacial pain-dysfunction (MPD) syndrome: a comparative study. J. Am. Dent. Assoc., 84(3):624-8, 1972.

Hasegawa, K.; Okamoto, M.; Nishigawa, G.; Oki, K. \& Minagi, $\mathrm{S}$. The design of non-occlusal intraoral appliances on hard palate and their effect on masseter muscle activity during sleep. Cranio, 25(1):8-15, 2007.

Klasser, G. D. \& Greene, C. S. The changing field of temporomandibular disorders: what dentists need to know. J. Can. Dent. Assoc., 75(1):49-53, 2009.

Leeuw, R. Dor Orofacial: Guia de Avaliação, Diagnóstico e Tratamento - Academia Americana de Dor Orofacial. 4a ed. São Paulo, Quintessence, 2010.

Maciel, R. N. \& Gil, A. R. Placas Oclusais. In: Maciel, R. N. (Ed.). Bruxismo. São Paulo, Artes Médicas, 2010. pp.471-503.

Minagi, S.; Shimamura, M.; Sato, T.; Natsuaki, N. \& Ohta, M. Effect of a thick palatal appliance on muscular symptoms in craniomandibular disorders: a preliminary study. Cranio, 19(1):42-7, 2001.

Okeson, J. P. Tratamento das Desordens Temporomandibulares e Oclusão. Rio de Janeiro, Elsevier, 2008.

Palla, S. Mioartropatias do Sistema Mastigatório e Dores Orofaciais. São Paulo, Artes Médicas, 2004.

Sessle, B. J.; Lavigne, G. J.; Lund, J. P. \& Dubner, R. Dor orofacial - da ciência básica à conduta clínica. $2^{\mathrm{a}}$ ed. São Paulo, Quintessence, 2010.

Tsuga, K.; Nakahara, Y.; Shitozawa, S.; Tamura, H.; Matsuda, K.; Fujioka, M.; Nagasawa, T. \& Tsuru, H. The influence of palatal plate thickness on functional mandibular movement. Hiroshima Daigaku Shigaku Zasshi, 18(2):351-5, 1986.
Correspondence to:

Prof. Dr. Antônio Sérgio Guimarães Instituto da Cabeça

Universidade Federal de São Paulo

Escola Paulista de Medicina

São Paulo

BRAZIL

Email: drsuazo2000@yahoo.es

Received: 25-02-2012

Accepted: 12-08-2013 